\title{
Reduced Slc6a15 in Nucleus Accumbens D2-Neurons Underlies Stress Susceptibility
}

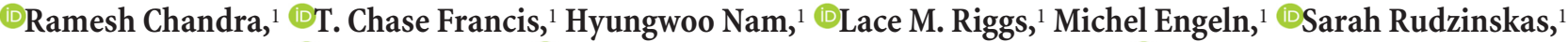 \\ Prasad Konkalmatt, ${ }^{2}$ DScott J. Russo, ${ }^{3}{ }^{\mathbb{D}}$ Gustavo Turecki, ${ }^{4}$ Sergio D. Iniguez, ${ }^{5}$ and ${ }^{D}$ Mary Kay Lobo ${ }^{1}$ \\ ${ }^{1}$ Department of Anatomy and Neurobiology, University of Maryland School of Medicine, Baltimore, Maryland 21201, ${ }^{2}$ Division of Renal Diseases and \\ Hypertension, The George Washington University, Washington, DC 20037, ${ }^{3}$ Fishberg Department of Neuroscience and Friedman Brain Institute, Graduate \\ School of Biomedical Sciences at the Icahn School of Medicine at Mount Sinai, New York, New York 10029, ${ }^{4}$ McGill Group for Suicide Studies, Douglas \\ Mental Health University Institute, McGill University, Montréal, Québec H4H 1R3, Canada, and 5Department of Psychology, University of Texas at El Paso, \\ El Paso, Texas 79968
}

Previous research demonstrates that Slc6a15, a neutral amino acid transporter, is associated with depression susceptibility. However, no study examined Slc6a15 in the ventral striatum [nucleus accumbens (NAc)] in depression. Given our previous characterization of Slc6a15 as a striatal dopamine receptor 2 (D2)-neuron-enriched gene, we examined the role of Slc6a15 in NAc D2-neurons in mediating susceptibility to stress in male mice. First, we showed that Slc6a15 mRNA was reduced in NAc of mice susceptible to chronic social defeat stress (CSDS), a paradigm that produces behavioral and molecular adaptations that resemble clinical depression. Consistent with our preclinical data, we observed Slc6a15 mRNA reduction in NAc of individuals with major depressive disorder (MDD). The Slc6a15 reduction in NAc occurred selectively in D2-neurons. Next, we used Cre-inducible viruses combined with D2-Cre mice to reduce or overexpress Slc6a15 in NAc D2-neurons. Slc6a15 reduction in D2-neurons caused enhanced susceptibility to a subthreshold social defeat stress (SSDS) as observed by reduced social interaction, while a reduction in social interaction following CSDS was not observed when Slc6a15 expression in D2-neurons was restored. Finally, since both D2-medium spiny neurons (MSNs) and D2-expressing choline acetyltransferase (ChAT) interneurons express Slc6a15, we examined Slc6a15 protein in these interneurons after CSDS. Slc6a15 protein was unaltered in ChAT interneurons. Consistent with this, reducing Slc5a15 selectively in NAc D2-MSNs, using A2A-Cre mice that express Cre selectively in D2-MSNs, caused enhanced susceptibility to SSDS. Collectively, our data demonstrate that reduced Slc6a15 in NAc occurs in MDD individuals and that Slc6a15 reduction in NAc D2-neurons underlies stress susceptibility.

Key words: depression; medium spiny neurons; nucleus accumbens; Slc6a15; social defeat stress

\section{Significance Statement}

Our study demonstrates a role for reduced Slc6a15, a neutral amino acid transporter, in nucleus accumbens (NAc) in depression and stress susceptibility. The reduction of Slc6a15 occurs selectively in the NAc D2-neurons. Genetic reduction of Slc6a15 induces susceptibility to a subthreshold stress, while genetic overexpression in D2-neurons prevents social avoidance after chronic social defeat stress.

\section{Introduction}

Depression is a devastating illness whose complex etiology makes it difficult to treat (Han et al., 2013). One reason for this is that we

Received 0ct. 20, 2016; revised April 18, 2017; accepted May 19, 2017.

Author contributions: R.C., T.C.F., H.N., L.M.R., S.D.I., and M.K.L. designed research; R.C., T.C.F., H.N., L.M.R., M.E., S.R., and M.K.L. performed research; P.K., G.T., and S.J.R. contributed reagents/analytic tools; R.C., T.C.F., H.N., L.M.R., and M.K.L. analyzed data; R.C. and M.K.L. wrote the paper.

This work is supported by National Institutes of Health/National Institute of Mental Health Grant R01-MH106500 (M.K.L), and Brain \& Behavior Research Foundation NARSAD Young Investigator Award, P\&S Fund (R.C.).

The authors declare no competing financial interests.

Correspondence should be addressed to Dr. Mary Kay Lobo, Department of Anatomy and Neurobiology, University of Maryland School of Medicine, 20 Penn Street, HSF II Room S251, Baltimore, MD 21201. E-mail: mklobo@som.umaryland.edu. lack a comprehensive understanding of the vulnerable neuron subtypes and their molecular correlates in depression. Insight into the molecular determinants of depression, in stress-susceptible neuron populations, could provide potential molecules to target for therapeutic treatment of depression. Members of the Slc6 neuronal transporter family, known as the neurotransmitter-sodium-symporter family, are implicated in major depression (Hahn and Blakely, 2007; Bröer, 2013; Rudnick et al., 2014). Recent data suggest that Slc6a15, a neutral amino acid transporter, is a risk gene for major

D0I:10.1523/JNEUROSCI.3250-16.2017

Copyright (c) 2017 the authors $\quad 0270-6474 / 17 / 376527-12 \$ 15.00 / 0$ 
depressive disorder (MDD; Kohli et al., 2011). Homozygote carriers of an A-allele of a single nucleotide polymorphism in a regulatory region of Slc6a15 have a higher risk for depression and depression symptoms compared with those homozygous for the G-allele or heterozygotes (Kohli et al., 2011; Schuhmacher et al., 2013). Homozygote risk allele carriers have decreased Slc6a15 mRNA, display altered hippocampal and anterior cingulate volume, and have changes in hippocampal metabolites (Kohli et al., 2011; Li et al., 2013). However, a recent study (Santarelli et al., 2016) showed that Slc6a15 knock-out mice display reduced anxiety- and depressive-like behavior after stress and that Slc6a15 overexpression in hippocampus resulted in increased anxietylike behavior. Overall, these studies examining the relationship between Slc6a15 and depression have focused exclusively on the hippocampus as the primary target of investigation. However, Slc6a15 is expressed in a number of brain regions involved in emotional behavior such as the cortex, striatum, amygdala, and ventral tegmental area (Lobo et al., 2006; Hägglund et al., 2013).

The ventral striatum, or nucleus accumbens (NAc) is a candidate for Slc6a15 investigation given that the NAc is strongly implicated in the hallmark symptoms of MDD, such as reduced motivation and anhedonia (Eichler and Antelman, 1979; Zacharko et al., 1987; Willner et al., 1992; Berton et al., 2006; Krishnan et al., 2007; Vialou et al., 2011; Russo and Nestler, 2013; Dias et al., 2014; Francis et al., 2015). NAc neurons play a key role in mediating depression symptomatology in preclinical and clinical conditions through altered molecular and cellular adaptations (Berton et al., 2006; Vialou et al., 2011; Russo and Nestler, 2013; Dias et al., 2014; Francis et al., 2015). We previously found Slc6a15 mRNA to be enriched selectively in striatal dopamine receptor 2 (D2)expressing neurons (Lobo et al., 2006). D2 is expressed in both D2-medium spiny neurons (MSNs), one of the two main projection neuron subtypes in dorsal and ventral striatum, as well as in choline acetyltransferase (ChAT) interneurons (Alcantara et al., 2003). Both populations of D2-neurons play important roles in depressive-like behavior (Warner-Schmidt et al., 2012; Lobo et al., 2013; Dias et al., 2014; Francis et al., 2015; Virk et al., 2016). Thus, we examine the role for Slc6a15 in NAc in depression and selectively examine Slc6a15 in D2-neurons in mediating behavioral states to chronic social defeat stress (CSDS). This paradigm produces behavioral and molecular adaptations that resemble clinical depression in a subset of mice (susceptible mice), while a subgroup of mice (resilient mice) do not display depression-like behavior (Krishnan et al., 2007). First, we examined Slc6a15 mRNA in NAc after CSDS and in postmortem NAc of individuals with MDD. We then investigated Slc6a15 ribosome-associated mRNA and protein in NAc D2-neurons following CSDS. To determine the role of Slc6a15 in D2-neurons in stress susceptibility, we selectively manipulated the expression of Slc6a15 in these neurons by injecting Cre-inducible adeno-associated viruses (AAVs) into the NAc of D2-Cre mice. Finally, we investigated Slc6a15 in ChAT interneurons after CSDS and confirmed D2-MSN Slc6a15 selectivity in depression-like behavior. Together, our results show that reduced Slc6a15 expression within the NAc mediates susceptibility to depression and that this effect occurs selectively within the D2-MSN population.

\section{Materials and Methods}

Animals. Male, D2-Cre hemizygote (line ER44; RRID: MMRRC_032108UCD), or A2A-Cre hemizygote (line KG139; RRID: MMRRC_031168UCD), or D2-GFP (line S118; RRID: MMRRC_036931-UCD) bacterial artificial chromosome transgenic mice from GENSAT (Gong et al., 2003, 2007; Gerfen et al., 2013; www.gensat.org) on a C57BL/6J background were used for CSDS or subthreshold social defeat stress (SSDS) defeat behavioral experiments and for immunohistochemistry (IHC). Homozygous RiboTag (RT) mice on a C57BL/6J background expressing a Cre-inducible hemagglutinin (HA)-Ribosomal Protein L22 (Rpl22; RRID: JAX: 011029; Sanz et al., 2009) were crossed with D2-Cre or D1-Cre (line FK150; MMRRC_036916-UCD; Gong et al., 2007; Gerfen et al., 2013) mouse lines to generate D1-Cre-RT and D2-Cre-RT mice (Chandra et al., 2015) and used for CSDS followed by cell type-specific ribosome-associated mRNA isolation. Male C57BL/6J mice (RRID: IMSR_JAX:000664) obtained from The Jackson Laboratory were used for behavioral experiments and RT-PCR. Aggressive retired male CD1 mice obtained from Charles River were used for social defeat. All mice were maintained on a $12 \mathrm{~h}$ light/dark cycle ad libitum food and water. All studies were conducted in accordance with the guidelines set up by the Institutional Animal Care and Use Committee at The University of Maryland School of Medicine.

Chronic social defeat stress. D2-Cre, D2-GFP, D2-Cre-RT, D1-Cre-RT, and C57BL/J mice underwent $10 \mathrm{~d}$ CSDS. This is a well established protocol that yields stress-susceptible (mice displaying depression-like behaviors) or resilient cohorts (Krishnan et al., 2007; Francis et al., 2015). Experimental mice were exposed to an aggressive retired CD1 breeder for $10 \mathrm{~min} / \mathrm{d}$ and then housed within the same cage as the CD1 on the opposite side of a perforated divider to maintain sensory contact. This was repeated for $10 \mathrm{~d}$ with a novel CD1 mouse on each day. On day 11, mice were screened for social interaction (SI) behavior. Animals were placed in an open field with a perforated box located in a designated interaction zone for $2.5 \mathrm{~min}$ and assessed for time spent in the interaction zone using TopScan video tracking software (CleverSys). This behavioral control, designated as "no target," was used to determine the baseline interaction with the perforated box that will subsequently house a novel social target. Following the "no target" condition, a novel CD1 was placed in the perforated box and experimental mice were assessed for time spent interacting with the novel social target, designated as "target," in the interaction zone during the 2.5 min time period. Mean interaction time was assessed in each experiment. For each experiment, animals were deemed susceptible if interaction times were 2 SDs below the mean of nondefeated control animals or resilient if they did not fall into this category (Francis et al., 2015). Representative heat density maps were exported from the start to the end of the session of SI by setting a fixed parameter of NormV 80, Inti contrast 5, filter 10, and Exposure factor 0.5.

Subthreshold social defeat stress. SSDS in D2-Cre and A2A-cre mice was administered in a manner similar to previously described methods (Francis et al., 2015). Briefly, mice were exposed to three sessions of novel CD-1 aggressors for $2 \mathrm{~min}$ per defeat, then mice were placed on the other side of a perforated divider to allow for sensory contact for $15 \mathrm{~min}$. After the SSDS, mice were returned to their home cage. SI was performed, as described above, the next day.

Viral placement validation. Following the behavioral experiments, mice were perfused; brains were removed, sectioned, and processed through immunohistochemistry (see Immunohistochemistry methods); and examined for expression and for the accuracy of the spread of the viral injections. Mice that did not display virus expression in NAc were removed from the study.

Human postmortem tissue. Whole-tissue NAc resections were collected by the Quebec Suicide Brain Bank at the Douglas Hospital Research Center under an approval from the Douglas Hospital Research Center Research Ethics Committee. The cohort was composed of 22 males and 11 females, ranging in age between 22 and 81 years. All of the subjects screened out by any history of neurological disorders, head injury, or use of psychotropic medications. Three to four mental health professionals performed an extensive review of the clinical information and made independent diagnoses followed by a consensus diagnosis of MDD using the Diagnostic and Statistical Manual of Mental Disorders IV criteria. The control group comprised 10 subjects with no history of dependence on illicit drugs and no major psychiatric diagnoses (Fig. 1D). Under the MDD cohort, 11 subjects had been receiving antidepressant medication, and 12 subjects were not receiving any medication. The processing of the 
A
10 minute

Physical

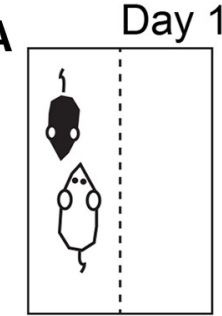

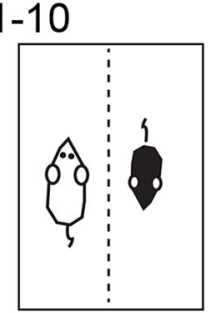

24 hour Sensory
Day 11

Social interaction

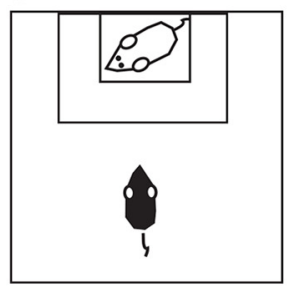

C
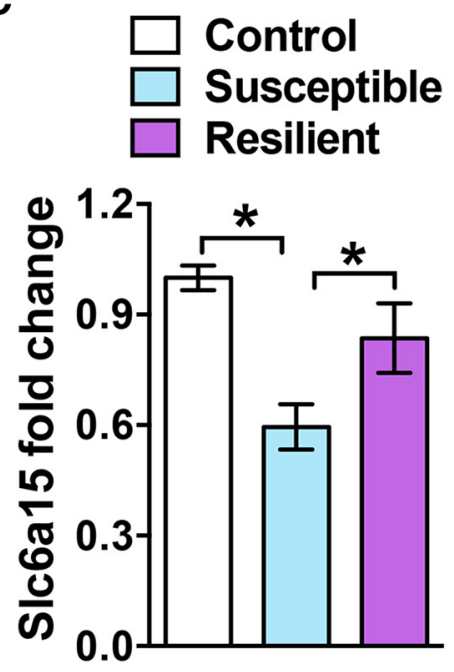

B
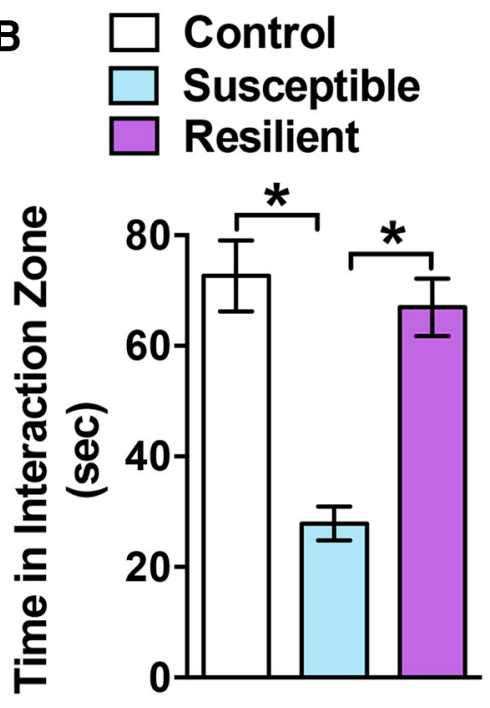
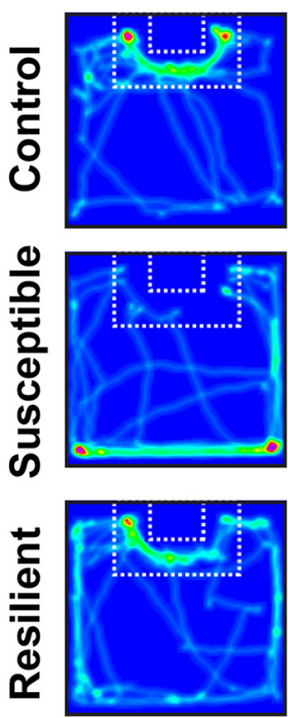

D

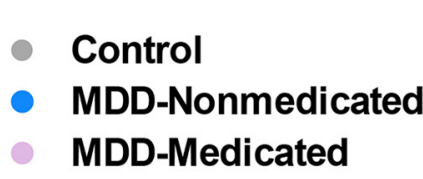

\begin{tabular}{|c|c|c|c|}
\hline & Control & \multicolumn{2}{|c|}{ MDD } \\
\hline & & $\begin{array}{c}\text { Antidepressant } \\
\text { OFF }\end{array}$ & $\begin{array}{c}\text { Antidepressant } \\
\text { ON }\end{array}$ \\
\hline Male & 7 & 8 & 7 \\
\hline Female & 3 & 3 & 5 \\
\hline
\end{tabular}

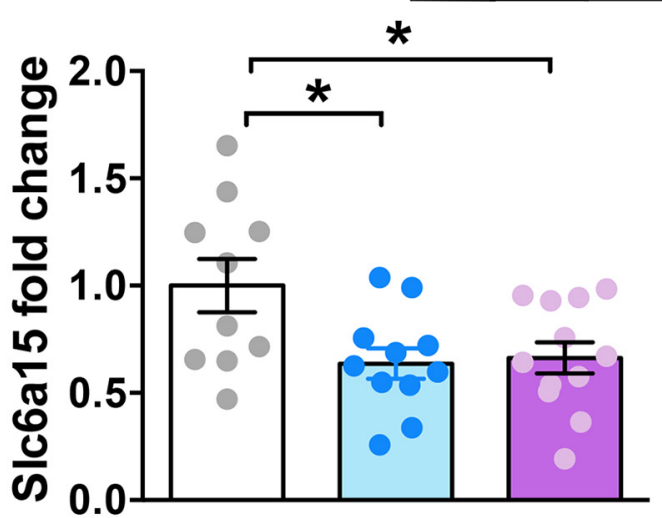

Figure 1. SIc6a15 is reduced in the stress-susceptible NAc and postmortem in NAc of individuals with major depressive disorder. $A$, Illustration of the CSDS experimental paradigm. Subject mice underwent $10 \mathrm{~d}$ of physical interaction with a novel aggressive CD1 mouse for $10 \mathrm{~min}$ each day. This is followed by sensory contact, on the other side of a perforated divider, for $24 \mathrm{~h}$ after each physical interaction. 0 nday 11 , mice are tested in a social interaction test with a novel mouse. $\boldsymbol{B}$, Susceptible mice display decreased time (in seconds) in the social interaction zone, interacting with the novel mouse, compared with control or resilient mice ( $n=12$ control mice; $n=11$ susceptible mice; and $n=10$ resilient mice). Heat map of the mouse video tracking control, susceptible, and resilient mice (right), which demonstrates increased time in the social interaction zone for control and resilient mice. In contrast, susceptible mice spent less time in this zone. C, S/c6a15 mRNA is reduced in NAc, $24 \mathrm{~h}$ after CSDS, of susceptible mice compared with resilient and nonstressed control mice ( $n=12$ control mice; $n=11$ susceptible mice; and $n=10$ resilient mice). D, Slc6a15 mRNA is decreased postmortem in NAc of individuals with MDD who committed suicide who were either ON or OFF antidepressant treatment $(n=10$ control subjects; $n=11$ individuals with MDD who were receiving medication; $n=12$ individuals with MDD who were receiving medication). The table (top) indicates the number of subjects and the sex in each group. ${ }^{*} p<0.05$. Error bars indicate SEM.

tissue has been described previously (Golden et al., 2013; Robison et al., 2014). Briefly, hemispheres were immediately separated by a sagittal cut into 1-cm-thick slices and placed in a mixture of dry ice and isopentane $(1: 1, \mathrm{v} / \mathrm{v})$. The frozen tissue was then stored at $-80^{\circ} \mathrm{C}$.

Adeno-associated viral vectors. Cre-dependent AAVs Slc6a15-tGFP, EYFP, Slc6a15micro-RNA(miR)-mCitrine and Scramble sequence (SS)miR-mCitrine were used in this study. The Slc6a15-tGFP sequence, purchased from Addgene, was PCR amplified (Phusion DNA Polymerase, New England Biolabs) and cloned into the EF1a-double-inverted open reading frame (DIO) vector. AAV-DIO-EYFP was used as a control in the behavioral studies. Both vectors were packaged into AAV (serotype 2) at the University of North Carolina Vector Core Facility. Slc6a15-miR was generated from Slc6a15 shRNA by conversion from shRNA to miR as described previously (Chandra et al., 2015). In brief, four Slc6a15 shRNA expression vectors were purchased from Origene and tested in the
Neuro2a cells (catalog \#CCL-131, ATCC; RRID: CVCL_0470). Neuro2a cells were maintained at $37^{\circ} \mathrm{C}, 5 \% \mathrm{CO}_{2}$ in DMEM with GlutaMAXI, $4500 \mathrm{mg} / \mathrm{L}$ glucose, and $110 \mathrm{mg} / \mathrm{L}$ sodium pyruvate (Invitrogen) supplemented with $10 \% \mathrm{v} / \mathrm{v}$ FCS (Invitrogen). The most efficient shRNA was chosen for miR engineering using the BLOCK-iT Pol II miR RNAi Expression Vector Kit (catalog \#K493600, Invitrogen). We designed two single-stranded DNA oligonucleotides, one encoding the target pre-miR top strand oligo and the other the bottom strand oligo compliment. Top and bottom strand oligos were annealed to generate a double-stranded oligonucleotide and cloned into the pcDNA-EmGFP-miR vector provided in the kit. Finally, Slc6a15-miR was PCR amplified and cloned into a destination Cre-inducible vector, AAV-DIO-mCitrine-driven hSyn promoter at NheI and StuI restriction sites. The SS was also converted into an SSmiR as described above and used as a control virus. Virus packaging for AAV-DIO-Slc6a15miR-mCitrine and AAV-DIO-SSmiR- 
A

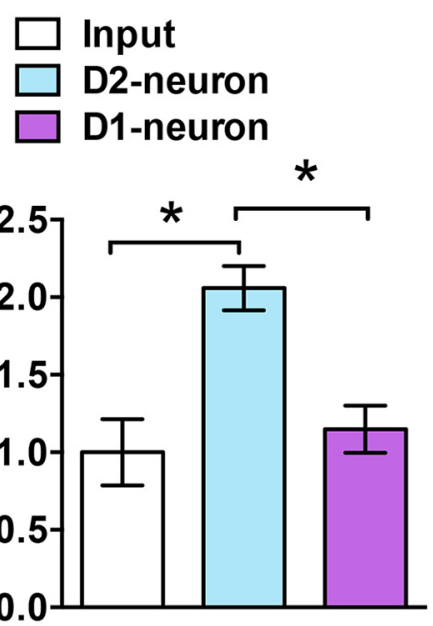

B

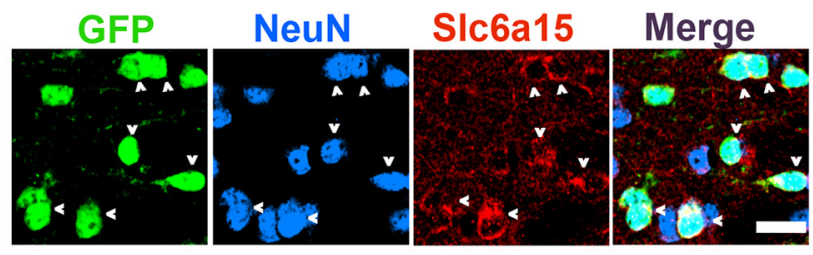

C

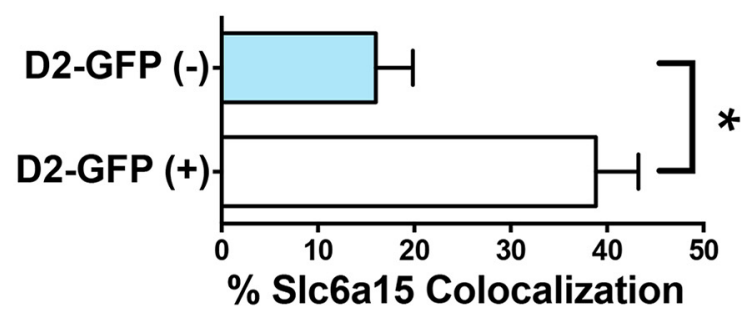

D

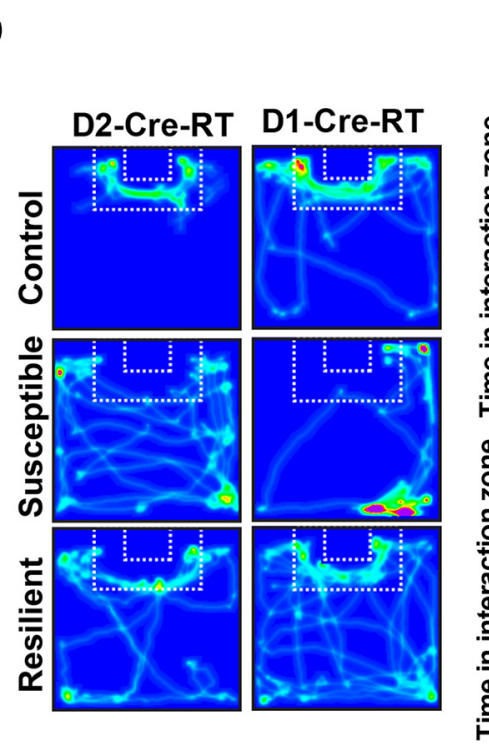

$\square$ Contro

Susceptible

Resilient
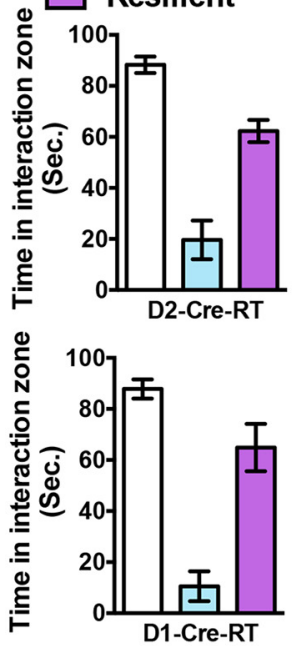

E
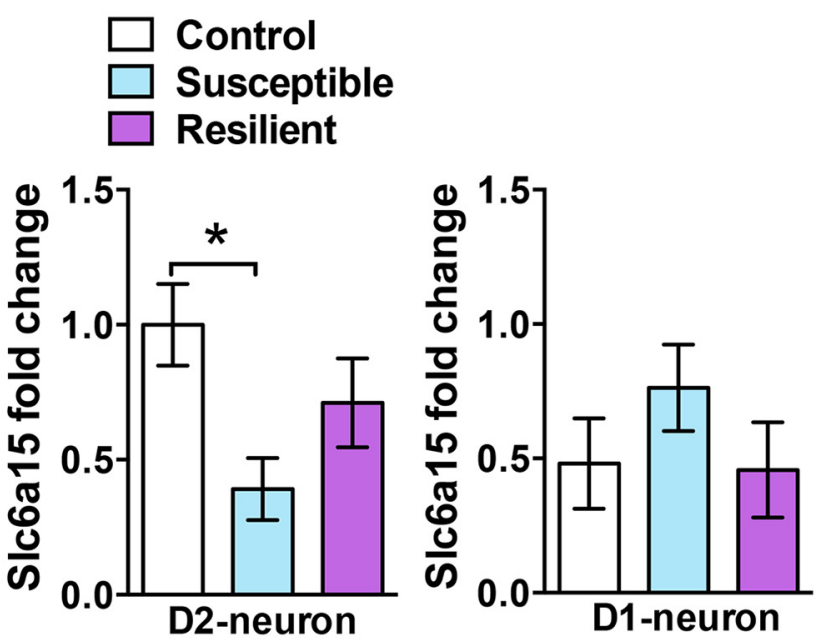
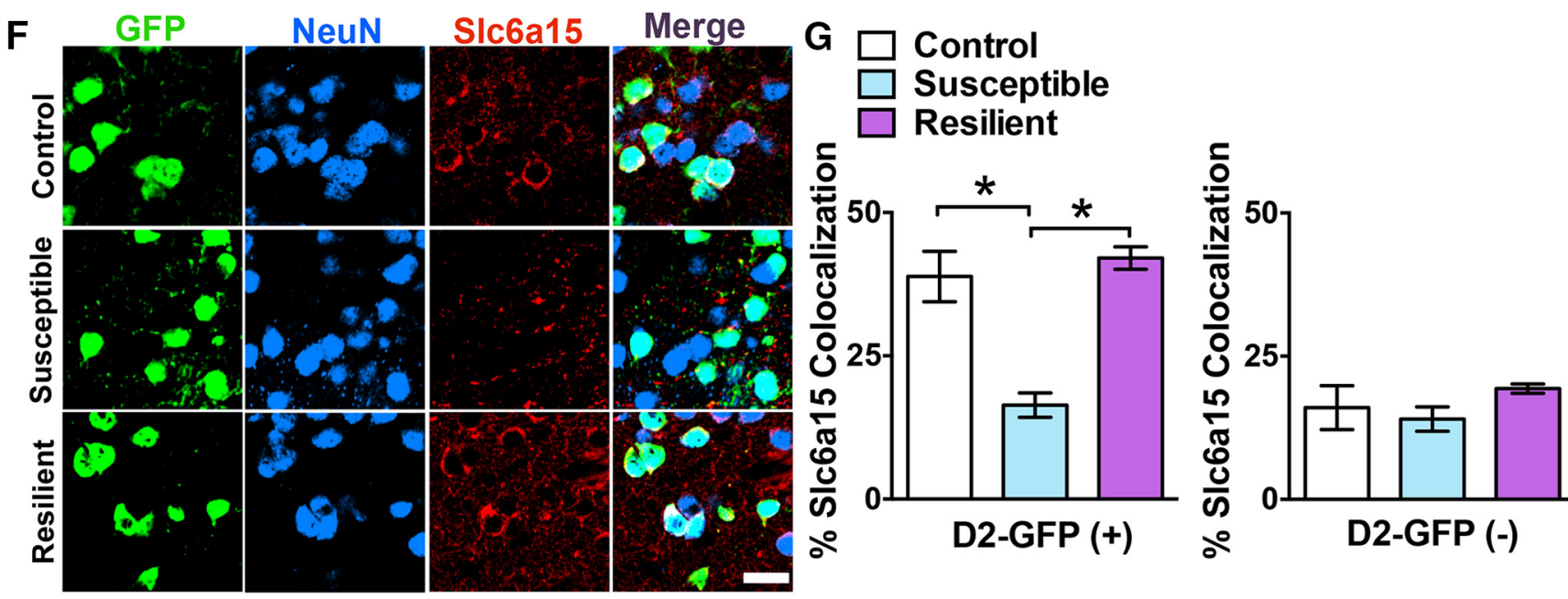

Figure 2. S/c6a15 mRNA and protein are enriched in NAC D2-neurons but reduced in NAC D2-neurons of CSDS-susceptible mice. A, S/c6a15 mRNA is enriched in NAC D2-neurons compared with D1-neurons and input (nonimmunoprecipitated mRNA) from each group ( $n=8$ input; $n=4$ D1-Cre-RT mice; and $n=4$ D2-Cre-RT mice). $B$, Representative D2-GFP NAc images after IHC with anti-NeuN (blue), anti-GFP (green) and anti-Slc6a15 (red). Arrows demonstrated colocalization of Slc6a15 with D2-GFP(+) neurons. Scale bar, $50 \mu \mathrm{m}$. C, Quantification of SIc6a15 neurons colocalized with D2-GFP( + ) and D2-GFP( - ). NAc neurons demonstrated that SIc6a15 colocalizes significantly more with D2-GFP $(+)$ neurons $(n=3$ per group). $D$, Heat map of the video tracking in control, susceptible, and resilient D2-Cre-RT and D1-Cre-RT mice during SI with a novel social target. Quantification of time spent (in seconds) in the interaction zone with the novel social target by controls, resilient mice, and susceptible mice. Susceptible mice display reduced time in the interaction zone ( $n=5$ controls; $n=5$ susceptible D2-Cre-RT mice; and $n=4$ resilient D2-Cre-RT mice; $n=5$ controls; $n=6$ susceptible D1-Cre-RT mice; and $n=3$ resilient D1-Cre-RT mice). $\boldsymbol{E}$, Cell-type-specific expression of Slc6a15 in NAc D2- and D1-neurons (Figure legend continues.) 
mCitrine (serotype 2) was performed as described previously (Chandra et al., 2015).

Mouse stereotaxic surgery. D2-Cre or A2A-Cre mice were anesthetized using $4 \%$ isoflurane in a small induction chamber. After the initial induction, isoflurane was maintained at $1 \%$ for the remainder of the surgery. Animals were placed in a stereotaxic instrument and their skull was exposed. The 33 gauge Hamilton syringe needles were used to inject $0.6 \mu \mathrm{l}$ of either AAV-DIO-tGFP or AAV-DIO-EYFP (D2-Cre mice) or AAV-DIO-Slc6a15miR-mCitrine or AAV-DIO-SSmiR-mCitrine (D2Cre or A2A-Cre mice) bilaterally into the NAc (in relation to bregma: anterior/posterior, $+1.6 \mathrm{~mm}$; medial/lateral, $\pm 1.5 \mathrm{~mm}$; dorsal/ventral, $-4.4 \mathrm{~mm} ; 10^{\circ}$ angle) according to our previous studies (Chandra et al., 2015; Francis et al., 2015). Mice were then returned to the vivarium for 2 weeks to allow for recovery and maximal virus expression.

Immunoprecipitation of polyribosomes and RNA isolation from MSN subtypes. D2-Cre-RT and D1-Cre-RT NAc tissue was collected using a 14 gauge punch $24 \mathrm{~h}$ after the SI and NAc punches were pooled from two mice with similar SI scores. Immunoprecipitation of polyribosome was prepared from NAc of D1-Cre-RT and D2-Cre-RT mice according to our previous study (Chandra et al., 2015). In brief, tissue was homogenized by douncing in $800 \mu \mathrm{l}$ of homogenization buffer, and clear supernatant was added to a tube containing anti-HA antibody (catalog \#MMS-101R, Covance; RRID:AB_10063630) for constant rotation overnight at $4^{\circ} \mathrm{C}$. The following day, $400 \mu \mathrm{l}$ of magnetic Dynabeads (100.03D, Invitrogen) was added in each sample for constant rotation overnight at $4^{\circ} \mathrm{C}$. The next day, beads were washed three times in high-salt buffer. Finally, RNA was extracted by adding TRK lysis buffer to the pellet provided in the MicroElute Total RNA Kit (OMEGA bio-tek) according to manufacturer instructions. RNA was quantified with a NanoDrop (Thermo Scientific). For cDNA synthesis and qRT-PCR results see below.

$R N A$ extraction and $q R T-P C R$. Mouse NAc tissue punches were collected $24 \mathrm{~h}$ after the SI and stored at $-80^{\circ} \mathrm{C}$. RNA was extracted using TRIzol (Invitrogen) and the MicroElute Total RNA Kit (Omega) with a DNase step (Qiagen). For human postmortem NAc tissue, total RNA was isolated by using TRIzol (Invitrogen) as described previously (Golden et al., 2013). RNA quantity was measured on a Nanodrop. Three hundred to four hundred nanograms of cDNA was then synthesized using a reverse-transcriptase iScript cDNA Synthesis Kit (BIO-RAD). mRNA expression changes were measured using quantitative PCR with PerfeCTa SYBR Green FastMix (Quanta). Quantification of mRNA changes was performed using the 2- $\Delta \Delta C_{\mathrm{T}}$ method, using glyceraldehyde-3phosphate dehydrogenase (GAPDH) as a housekeeping gene. The list of primers used in this study is as follows: Slc6a15 forward, AGGCACT GATACTGGGGAAAA; Slc6a15 reverse, TGGAGCCACTCCCATCA ATC; GAPDH forward, AGGTCGGTGTGAACGGATTTG; and GAPDH reverse, TGTAGACCATGTAGTTGAGGTCA.

Immunohistochemistry. All mice were perfused with $0.1 \mathrm{M}$ PBS followed by $4 \%$ paraformaldehyde (PFA). Brains were postfixed overnight in $4 \%$ PFA followed by cryoprotection in $30 \%$ sucrose and then sectioned on a cryostat (Leica) at $40 \mu \mathrm{m}$ into $0.1 \mathrm{M}$ PBS with azide. Sections were blocked in $3 \%$ normal donkey serum with $0.3 \%$ Triton-X for $30 \mathrm{~min}$ at room temperature followed by overnight incubation in primary antibodies in block. D2-GFP mice were incubated in 1:8000 chicken anti-GFP (catalog \#1020, Aves Labs; RRID: AB_10000240), 1:250 rabbit antiSlc6a15 (catalog \#SAB2102223, Sigma-Aldrich; RRID: AB_10606803),

$\leftarrow$

(Figure legend continued.) after CSDS demonstrates decreased SIc6a15 ribosome-associated mRNA in NAC D2-neurons of susceptible mice compared with resilient and control mice. However, Slc6a15 levels remain unchanged in NAc D1-neurons ( $n=5$ controls; $n=5$ susceptible D2-Cre-RT mice; and $n=4$ resilient D2-Cre-RT mice; $n=5$ controls; $n=6$ susceptible D1Cre-RT mice; and $n=3$ resilient D1-Cre-RT mice). $\boldsymbol{F}$, Representative D2-GFP NAcimages of (SDS control, susceptible, and resilient mice after IHC with anti-NeuN (blue), anti-GFP (green), and anti-Slc6a15 (red). Scale bar, $50 \mu \mathrm{m}$. G, Quantification of Slc6a15 colocalized neurons with D2-GFP(+) and D2-GFP(-) NAc neurons demonstrates reduced SIc6a15 colocalization with D2-GFP $(+)$ neurons in susceptible mice compared with control and resilient mice. No change is observed in D2-GFP( - ) neurons among the three groups. ( $n=3$ controls; $n=4$ susceptible; and $n=4$ resilient). ${ }^{*} p<0.05$. Error bars indicate SEM. and 1:1000 mouse anti-NeuN (catalog \#MAB377, Millipore; RRID: AB_2298772). Goat anti-ChAT (1:500; catalog \#AB144P, Millipore Bioscience Research Reagents; RRID: AB_2079751) was added for experiments analyzing ChAT interneurons. The next day, sections were rinsed three times in $0.1 \mathrm{M}$ PBS followed by $1 \mathrm{~h}$ incubation at room temperature in secondary antibodies in $0.1 \mathrm{M}$ PBS. The secondary antibodies (Jackson ImmunoResearch) used included the following: 1:1000 donkey antichicken Alexa Fluor 488; 1:1000 donkey anti-rabbit-Cy3; 1:1000 donkey anti-mouse Alexa Fluor 647; and 1:1000 donkey anti-goat-DyLight405. Sections were rinsed three times in $0.1 \mathrm{M}$ PBS, mounted onto slides, and coverslipped. D2-Cre and/or A2A-Cre mice expressing AAV-DIOSlc6a15miR-mCitrine, AAV-DIO-SSmiR-mCitrine, and AAV-DIO-EYFP were immunostained using procedures described above but with chicken anti-GFP and 1:500 rabbit anti-Slc6a15 only followed by corresponding secondary antibodies listed above. D2-Cre mice expressing AAV-DIOSlc6a15-tGFP were immunostained with similar procedures, but a rabbit anti-turboGFP (catalog \#EVN-AB513-C100, Axxora) was used followed by an anti-rabbit Alexa Fluor 488. Sections were then rinsed in PBS for $1 \mathrm{~h}$ (six times for 10 min each) and processed through a second immunostaining with rabbit anti-Slc6a15 and the corresponding secondary described above.

Cell counting. Immunofluorescence was imaged on an Olympus Bx61 Confocal Microscope. Cell counting was performed with ImageJ software (National Institutes of Health; RRID: SCR_003070). Images sampling NAc from 1.42 to $1.1 \mathrm{~mm}$ in relation to bregma were taken from two to three brain sections/animal. A total of 400-500 cells were counted per brain region per mouse using $250 \times 250 \mu \mathrm{m}$ images. Cells were counted using ImageJ software in a manner similar those used in previous studies (Lobo et al., 2013). Approximately 400-500 total NeuN cells were counted per brain region per mouse, and then the number of D2GFP(+), D2-GFP(+):Slc6a15(+), D2-GFP(-), and D2-GFP(-):Slc6a15(+) cells were counted in each region. For ChAT interneurons, the number of D2$\operatorname{GFP}(+): \operatorname{ChAT}(+)$ and D2-GFP(+):ChAT $(+): \operatorname{Slc6a15}(+)$ neurons were counted. Data were quantified by D2-GFP $(+)$ :Slc6a15 $(+)$ neurons $\times 100 \% /$ total D2-GFP $(+)$ neurons, D2-GFP $(-)$ :Slc6a15 $(+)$ neurons $\times 100 \% /$ total D2$\mathrm{GFP}(+)$ neurons, or D2-GFP $(+)$ :ChAT $(+)$ :Slc6a15 $(+)$ neurons $\times 100 \% /$ total D2-GFP $(+)$ :ChAT $(+)$ neurons.

Experimental design and statistical analysis. All experiments conducted in this study were designed to analyze between-subject effects. The effects of social defeat (Fig. $1 B-D$; also see Fig. $5 B$ ) and the effects of cell type (Fig. $2 A, D, E, G$ ) among three groups of subjects were analyzed using one-way ANOVA. Tukey's multiple-comparison tests were conducted post hoc when there was a statistical significance. The effects of social defeat across two different virus conditions (Figs. $3 H, I, 4 E, F, 5 E, F$ ) were analyzed using two-way ANOVA. Tukey's multiple-comparison tests were conducted post hoc when there was a significant interaction between the two factors. The effect of cell type (Fig. 2C) and the effect of virus microinjection (Figs. $3 E, 4 C$ ) between two groups of subjects was determined using two-tailed Student's $t$ test. A more detailed experimental design and statistical analysis can be found in the Results section describing specific figures. All statistical analyses were performed using GraphPad Prism version 6.0 software (RRID: SCR_002798). Data are presented as the mean $\pm \mathrm{SEM}$; significance was set at $p<0.05$.

\section{Results}

\section{Slc6a15 is reduced in NAc after social defeat stress and in major depressive disorder}

We first examined whether CSDS (Fig. 1A) alters the expression of Slc6a15 in NAc. We examined C57BL/6J mice that displayed susceptible and resilient behavior in response to CSDS. Susceptible mice displayed significantly less time interacting with a novel mouse compared with no-defeat control mice and resilient mice as observed in an SI test. A one-way ANOVA produced a significant effect $\left(F_{(2,30)}=22.18, p<0.0001\right)$, justifying a pairwise comparison using a Tukey's post hoc test that displayed a significance of $p<0.01$ when comparing susceptible mice to control or resilient mice $n=9-12$ per group (Fig. $1 B$ ). There was no difference in the time spent in the interaction zone or the distance 
A

ATG.. ...TGAATCTGTCAAAGACCTCCTGTCCAACGAAGACTCAGTGGAAGAGGTTTC. A

........CGGGAAGCACTGGATATCACCAGCTCCATCTCTGACAGTGGAGGCTTAAACTGGAA.......... ......AAAAGTGAAGGAGGAGGAGTTTGCTGTTCTTCATCTCAACGCCTGTCAAATTGAG D

ATAAGAGAGGAAGAGTCCTGAAGGAACCTGTGAACTTGGAAGGAGATGACGCAAGCCTC......

C

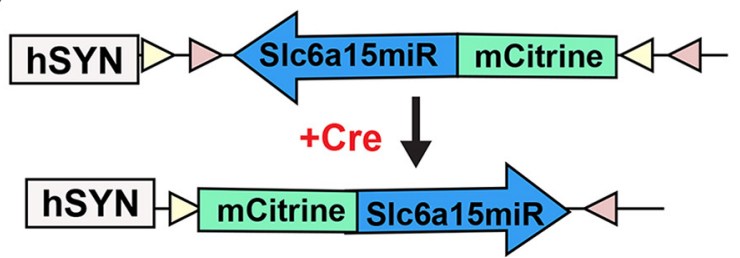

D

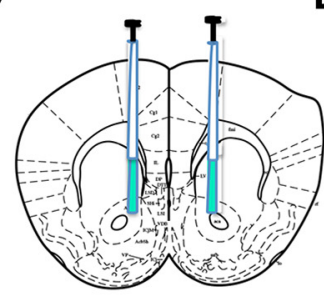

E

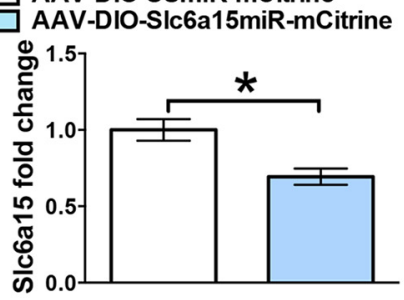

G

H

$\mathbf{F}$
B

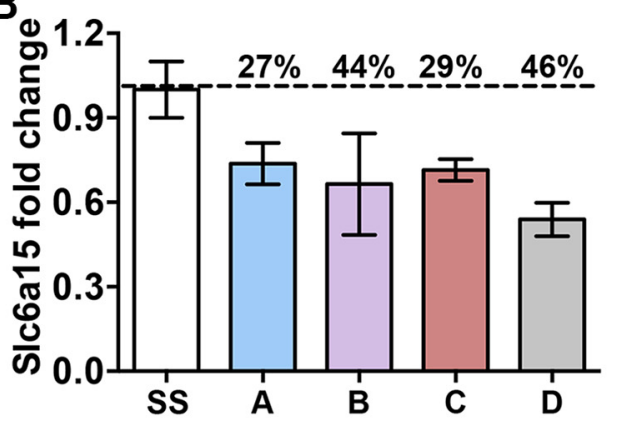

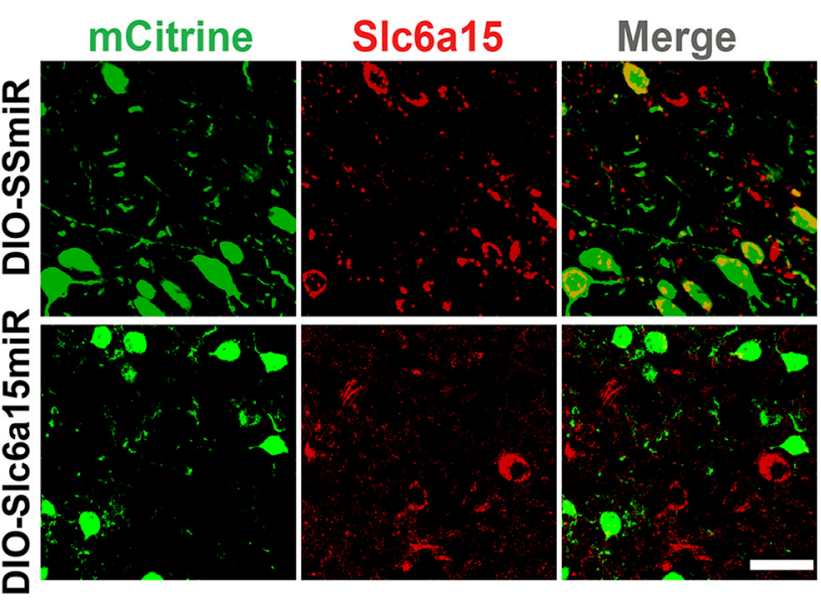

I

Day 1

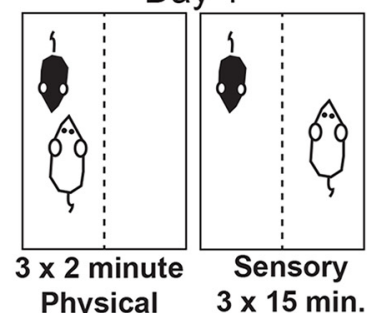

O AAV-DIO-SSmiR-mCitrine

O AAV-DIO-SIc6a15miR-mCitrine

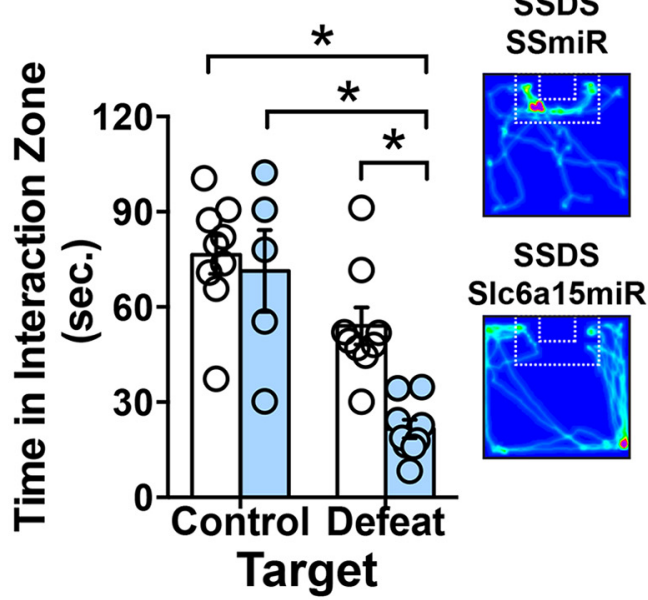

O AAV-DIO-SSmiR-mCitrine O AAV-DIO-SIc6a15miR-mCitrine

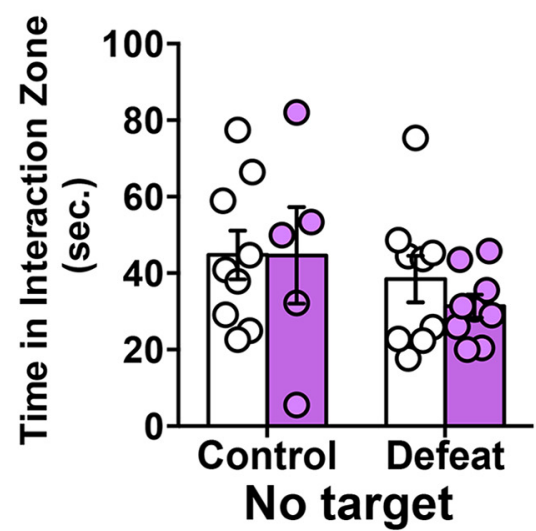

Figure 3. Genetic reduction of SIc6a15 in D2-neurons induces susceptibility to a subthreshold social defeat stress. $\boldsymbol{A}$, Mouse SIc6a15 shRNA sequences and their targets on the SIc6a15 gene. $\boldsymbol{B}$, qRT-PCR analysis of SIc6a15 demonstrates sufficient SIc6a15 shRNA knockdown in Neuro2a cells. $\boldsymbol{C}$, Schematic of the double-floxed, inverted, open reading frame Cre-dependent AAV vector expressing SIc6a15miR-mCitrine. D, Illustration of bilateral infusion of AAVs into NAc. $\boldsymbol{E}$, D2-Cre mice receiving AAV-DI0-SIc6a15miR-mCitrine to NAc display reduced S/c6a15 mRNA in NAc ( $n=4$ per group). $F$, IHC in SIc6a15miR and SSmiR injected NAc in D2-Cre mice, mCitrine (green) and SIc6a15 (red), demonstrates reduced SIc6a15 in SIc6a15miR-mCitrine expressing D2-neurons. Scale bar, $50 \mu \mathrm{m}$. G, Illustration of the SSDS experimental paradigm. Subject mice underwent 1 day of 3 physical interactions with a novel aggressive CD1 for 2 min each day. This is followed by sensory contact, on the other side of a perforated divider, for 15 min after each physical interaction. 0 n day 2 , mice are tested in a social interaction test with a novel mouse. $\boldsymbol{H}$, D2-Cre mice receiving AAV-DI0-SIC6a15miR-mCitrine to NAc display reduced time interacting with a novel mouse (Target) compared to mice receiving AAV-DI0SSmiR-mCitrine or non-stressed control mice after SSDS ( $n=9$ control SSmiR, $n=9$ defeat SSmiR, $n=5$ control SIc6a15miR, $n=9$ defeat SIc6a15miR). Heat density map of video tracking of SSDS SIc6a15miR injected or SSmiR injected D2-Cre mice (right panel). $I$, Time spent in the interaction zone without a novel mouse (No Target) is unchanged between all groups. ${ }^{*} p<0.05$, Error bars indicate SEM. 
A AAV-DIO-SIc6a15-tGFP

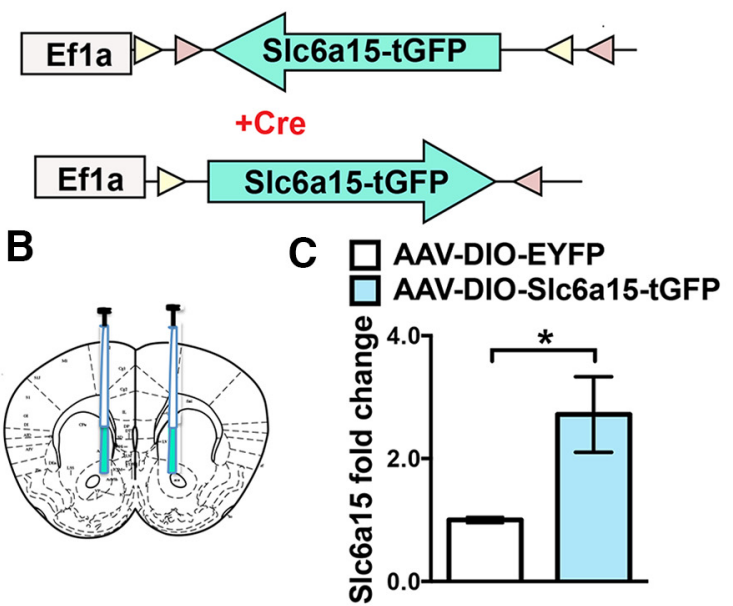

E

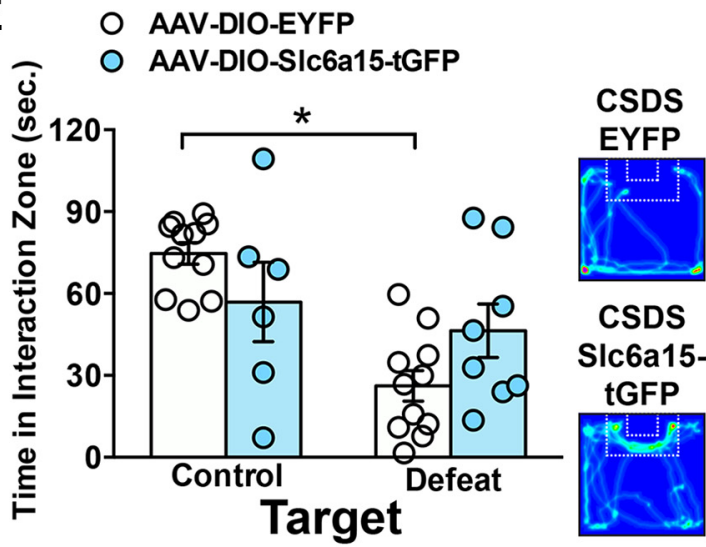

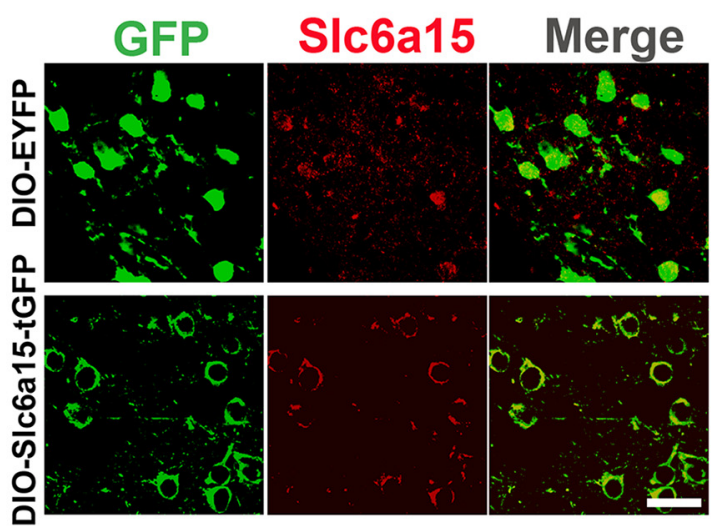

$\mathbf{F}$

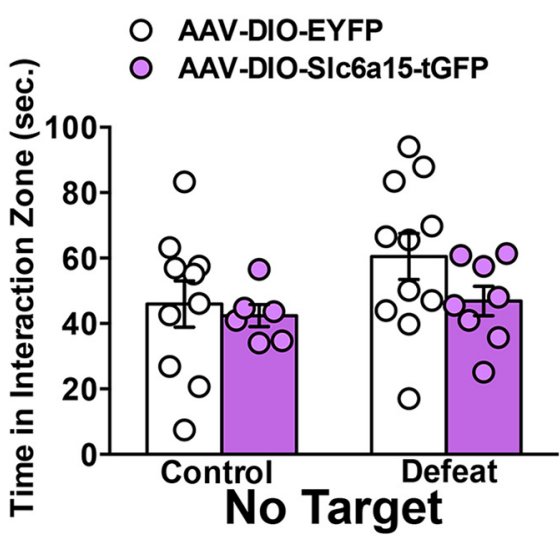

Figure 4. Overexpression of SIc6a15 in D2-neurons prevents social avoidance after chronic social defeat stress. $A$, Schematic of the double-floxed, inverted, open reading frame Cre-dependent AAV vector expressing SIc6a15-tGFP. B, Illustration of bilateral infusion of virus into NAc. C, D2-Cre mice expressing AAV-DI0-SIc6a15-tGFP in NAc display increased the SIc6a15 mRNA compared with AAV-DI0-EYFP controls ( $n=5$ EYFP; $n=4$ SIc6a15-tGFP). D, Immunohistochemistry with tGFP or GFP (green) and SIc6a15 (red) in NAc of D2-Cre mice demonstrates high colocalization of SIc6a15 (red) with SIc6a15-tGFP (green). Scale bar, $50 \mu \mathrm{m}$. E, D2-Cre mice with SIc6a15-tGFP in D2-neurons that underwent CSDS display a time spent in the interaction zone (in seconds), with a social target present, that is comparable to nonstressed control conditions, while D2-Cre mice expressing EYFP in D2-neurons display reduced time in the interaction zone $(n=11$ control EYFP mice; $n=11$ defeat EYFP mice; $n=6$ control SIc6a15-tGFP mice; and $n=8$ defeat SIc6a15-tGFP mice). Heat-density maps of video tracking in D2-Cre CSDS SIc6a15-tGFP and EYFP mice during SI (right). $\boldsymbol{F}$, Time spent in the interaction zone without a novel mouse (No Target) is unchanged among all groups. ${ }^{*} p<0.05$. Error bars indicate SEM.

moved when a novel mouse was not present during the SI test among all three groups (data not shown). At $24 \mathrm{~h}$ after the SI test, we collected NAc tissue for mRNA analysis. We observed a significant decrease in Slc6a15 mRNA in NAc of susceptible mice compared with no-defeat controls and resilient mice by performing a one-way $\operatorname{ANOVA}\left(F_{(2,30)}=10.45, p<0.001\right)$. This significant effect in the ANOVA justified a pairwise comparison using a Tukey's post hoc test that was significant $(p<0.05)$ when comparing susceptible mice to control and resilient mice $(n=9-12 /$ group; Fig. 1C). Next, we examined Slc6a15 mRNA in postmortem NAc of individuals with MDD who committed suicide or control subjects ( $n=10-12$ /group; Fig. $1 D$ ). Slc6a15 mRNA was significantly reduced in NAc of both groups of individuals with MDD who were not receiving antidepressant medication and were receiving antidepressant medication compared with control subjects. Significance was observed by one-way ANOVA $\left(F_{(2,30)}=4.83, p<0.05\right)$, which justified a pairwise comparison with a Tukey's post hoc test that displayed significance of $p<0.05$ when comparing the groups of individuals with MDD who were not receiving antidepressant medication and were receiving antidepressant medication compared with the control group (Fig. 1D).
Slc6a15 is enriched in NAc D2-neurons but reduced in D2-neurons after stress

Since our previous study (Lobo et al., 2006) demonstrated that Slc6a15 is increased in D2-neurons in the striatum, we examined Slc6a15 in these neurons in the NAc after stress. We first tested whether Slc6a15 levels are enhanced in D2-neurons selectively in NAc. We measured Slc6a15 mRNA expression in NAc D2- and D1-neurons using the RT methodology (Sanz et al., 2009; Chandra et al., 2015). To examine cell type-specific mRNA expression of Slc6a15, we crossed RiboTag (RT) mice that have a Creinducible HA-tagged Rpl22 with either D2- or D1-Cre mouse lines (Chandra et al., 2015). We isolated ribosome-associated mRNA through immunoprecipitation of either D2- or D1neuron polyribosomes that are labeled with the HA protein. We previously demonstrated enrichment of D2- or D1-neuronenriched genes in each neuron population in NAc using the D2Cre-RT or D1-Cre-RT mice, respectively (Chandra et al., 2015). Using qRT-PCR, we found that Slc6a15 ribosome-associated mRNA is increased in NAc D2-neurons of D2-Cre-RT mice, whereas no difference in Slc6a15 mRNA is detected in NAc D1-neurons of D1-Cre-RT mice compared with input mRNA (nonimmunoprecipitated mRNA) from both groups. Significance was detected by 
A

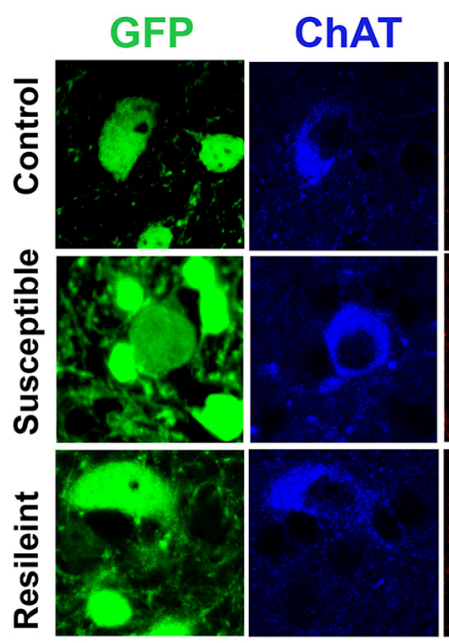

C
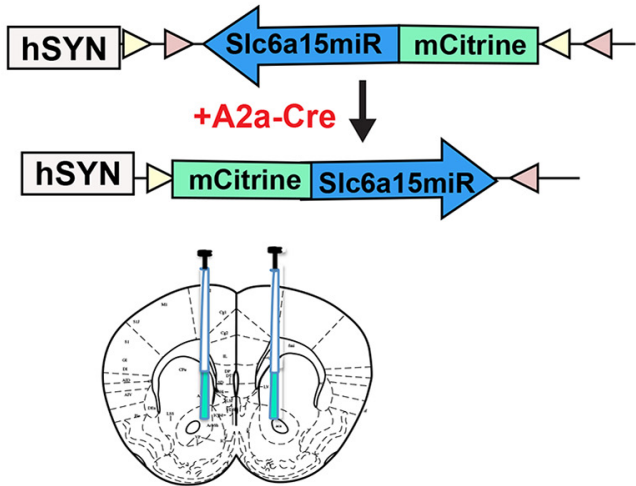

$\mathrm{E}$

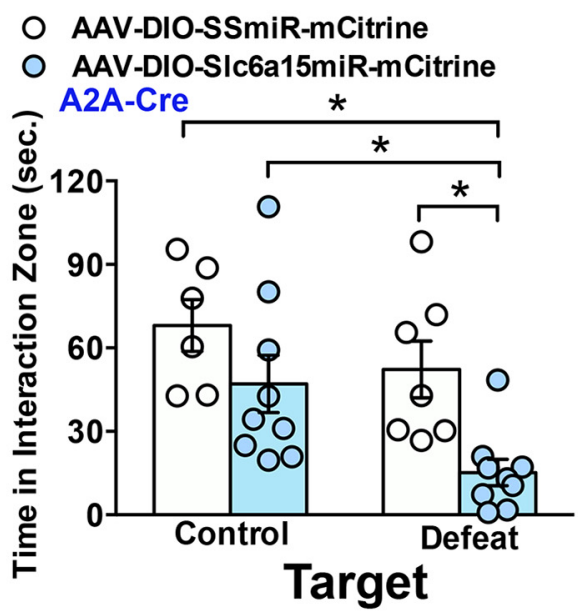

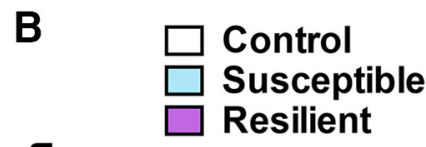

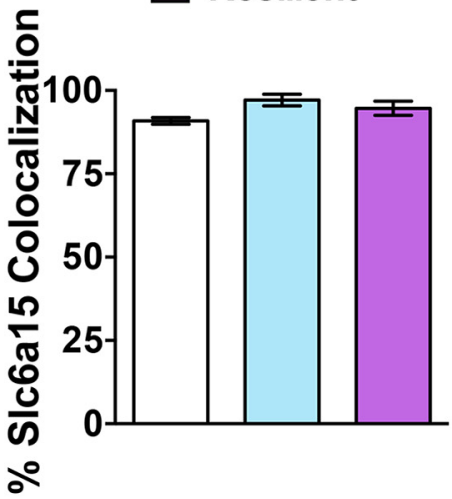

F

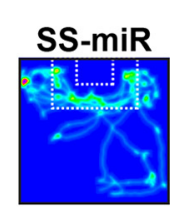

Slc6a15miR

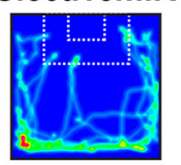

O AAV-DIO-SSmiR-mCitrine

O AAV-DIO-SIc6a15miR-mCitrine

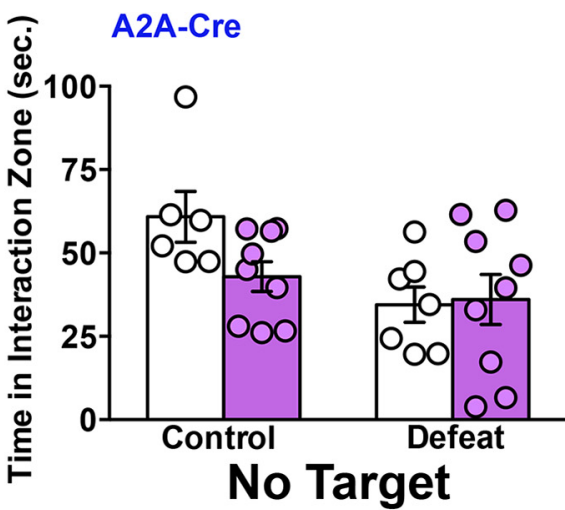

Figure 5. SIc6a15 is unaltered in ChAT interneurons and SIc6a15 reduction selectively in D2-MSNs induces susceptibility to SSDS.A,IHC in D2-GFPNAc, after CSDS, shows anti-SIc6a15 (red) colocalization with ChAT (blue) and D2-GFP (green) neurons in control, susceptible, and resilient mice. Scale bar, $10 \mu \mathrm{m}$. B, Slc6a15 colocalization is unaltered in ChAT interneurons in CSDS-susceptible or CSDS-resilient mice compared with nonstressed controls ( $n=3$ controls; $n=4$ CSDS-susceptible mice; and $n=4$ CSDS-resilient mice). C, Schematic of the double-floxed, inverted, open reading frame Cre-dependent AAV vector expressing Slc6a15miR-mCitrine. Illustration of bilateral infusion of AAVs into NAc. D, IHC in SIc6a15miR- and SSmiR-injected NAc in A2A-Cre mice, mCitrine (green), and Slc6a15 (red) demonstrates reduced Slc6a15 in SIc6a15miR-mCitrine expressing D2-neurons. Scale bar, $50 \mu \mathrm{m}$. E, A2A-Cre mice receiving AAV-DI0-SIc6a15-miR-mCitrine to NAc display reduced time in the interaction zone with the novel social target present (Target) afterSSDS, compared with SSmiR controls ( $n=6$ control SSmiR mice; $n=7$ defeatSSmiR mice; $n=9$ control Slc6a15miR mice; and $n=8$ defeatSIc6a15miR). Heat density map ofvideo tracking of SIc6a15-miR- and SSmiR-injected A2A-Cre mice in the presence of a novel social target (right). F, AAV-SIc6a15-miR expression in NAc D2-MSNs of A2A-Cre mice that underwent SSDS does not alter the time spent in the interaction zone when the target is absent (№ Target). ${ }^{*} p<0.05$. Error bars indicate SEM.

a one-way ANOVA $\left(F_{(2,13)}=6.60, p<0.01\right)$. This justified a pairwise comparison using a Tukey's post hoc test, resulting in significance of $p<0.05$ when comparing D2-neurons to input or D1-neurons ( $n=4-8$ per group, with two mice pooled per sample; Fig. 2A). Next, we used IHC to examine Slc6a15 protein in
D1- and D2-neurons of the NAc of D2-GFP mice (Fig. 2B). Sections were immunostained with anti-GFP, anti-NeuN, and antiSlc6a15, and Slc6a15-positive neurons were counted in the D2-GFP $(+)$ neurons or D2-GFP(-) neurons. We observed significantly higher Slc6a15 colocalization with D2-GFP $(+)$ neurons 
(38.84\% colocalized) when compared with D2-GFP(-) neurons $(16.02 \%$ colocalized) in NAc when using a Student's $t$ test $\left(t_{(4)}=6.75, p<0.05, n=3\right.$ per group; Fig. $\left.2 B\right)$.

To characterize the differences in Slc6a15 mRNA expression in D1- and D2-neurons as a function of stress, D1-Cre-RT and D2-Cre-RT mice were exposed to $10 \mathrm{~d}$ of CSDS (Fig. 2D). We observed a significant reduction of Slc6a15 ribosome-associated mRNA in NAc D2-neurons of susceptible mice compared with resilient and control mice, while no differences were observed in NAc D1-neurons. Using a one-way $\operatorname{ANOVA}\left(F_{(2,11)}=4.87\right)$, we observed a significance of $p<0.05$ in D2-neurons, but no significance was detected in D1-neurons $\left(F_{(2,11)}=1.05, p>0.05\right)$. We performed a pairwise comparison using a Tukey's post hoc test in the D2-neuron data, which yielded a significance of $p<0.05$ when comparing susceptible mice to control or resilient mice ( $n=3-6$ per group, two mice pooled per sample; Fig. $2 E$ ). Next, we used IHC to examine Slc6a15 protein in the NAc of D2-GFP mice that underwent CSDS. We observed a significant decrease in Slc6a15 colocalization with D2-GFP $(+)$ neurons in susceptible mice compared with resilient and nonstressed control mice, whereas no difference in Slc6a15 colocalization with D2-GFP (-) neurons was observed. Significance was detected using a one-way $\operatorname{ANOVA}\left(F_{(2,10)}=44.02, p<0.0001\right)$ for the D2-GFP $(+)$ neurons. D2-GFP $(-)$ neurons did not display a significant effect using a one-way $\operatorname{ANOVA}\left(F_{(2,10)}=2.49, p>0.05\right)$. A pairwise comparison using a Tukey's post hoc resulted in a significance of $p<0.05$ in the $\mathrm{D} 2(+)$ neurons when comparing susceptible mice to control or resilient mice ( $n=3-4$ per group; Fig. $2 F, G)$.

\section{Slc6a15 knockdown in D2-MSNs confers susceptibility to a subthreshold social defeat stress}

Since Slc6a15 mRNA and protein are reduced in D2-neurons of susceptible mice, we next sought to determine whether genetic reduction of Slc6a15 in D2-neurons confers stress susceptibility. A Cre-inducible AAV that expressed a Slc6a15miR was generated to selectively knock down Slc6a15 in D2-neurons using D2-Cre mice. To generate the Slc6a15miR, four predicted Slc6a15 shRNA sequences (A, B, C, and D) that target the mouse Slc6a15 were obtained from OriGene (Fig. 3A). A 46\% decrease of the Slc6a15 mRNA level was observed when using the shRNA-D sequence compared with the SS control in Neuro2A cells (Fig. 3B). The shRNA-D sequence and the SS sequence were converted into an miR and cloned into an AAV DIO-ires-mCitrine vector (Fig. 3C). AAV-DIO-Slc6a15miR-mCitrine and AAV-DIO-SSmiR were injected bilaterally into the NAc of D2-Cre mice (Fig. 3D). Slc6a15 mRNA was significantly reduced in NAc of mice receiving AAV-DIO-Slc6a15-miR-mCitrine compared with control virus using a Student's $t$ test $\left(t_{(6)}=1.81, p<0.05, n=4\right.$ per group; Fig. $3 E$ ). Additionally, using IHC, we demonstrated that Slc6a15miRmCitrine-expressing D2-neurons display less Slc6a15 colocalization, whereas SSmiR-expressing D2-neurons display colocalization with Slc6a15 (Fig. 3F). Two weeks after virus injection, mice underwent a SSDS, which consisted of three consecutive 2 min physical interaction sessions followed by $15 \mathrm{~min}$ sensory contact on the other side of a perforated divider (Fig. $3 G$ ). The next day mice underwent SI (Fig. 3G). D2-Cre AAV-DIO-Slc6a15miRmCitrine mice, which underwent SSDS, displayed significantly reduced time interacting with a novel social target compared with AAV-DIO-SSmiR-mCitrine SSDS mice and nonstressed control mice. A two-way ANOVA demonstrated a significant main effect of stress $\left(F_{(1,28)}=30.39, p<0.05\right)$ and a significant main effect of virus $\left(F_{(1,28)}=8.227, p<0.05\right)$. A significant interaction effect $\left(F_{(1,28)}=4.36, p<0.05\right)$ was observed. This justified a pairwise comparison using a Tukey's post hoc test, resulting in a significance of $p<0.05$, when comparing the Slc6a15-miR defeat group to all other groups $(n=5-9$; Fig. $3 H)$. Using a two-way ANOVA, we did not observe any significant main effect of stress $\left(F_{(1,28)}=\right.$ $2.13, p>0.5)$ and virus $\left(F_{(1,28)}=0.29, p>0.05\right)$ when the mice were tested in SI during the absence of a social target (Fig. 3I). Additionally, we examined the effects of Slc6a15 knockdown on general locomotor activity in the open field during the SI test. Our data demonstrated that there was no difference in locomotor activity between AAV-DIO-SSmiR- and AAV-DIO-Slc6a15miRinjected mice or the SSDS condition (control SSmiR, $7408.95 \pm$ $980.94 \mathrm{~mm}$; control Slc6a15miR, $6962.15 \pm 804.36 \mathrm{~mm}$; defeat

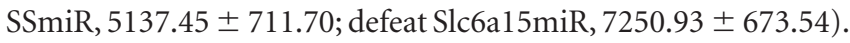
Analysis was performed with a two-way ANOVA, which demonstrated a lack of significant stress effect $\left(F_{(1,28)}=1.36, p>0.05\right)$ and virus effect $\left(F_{(1,28)}=0.96, p>0.05\right)$.

\section{Slc6a15 overexpression in D2-MSNs does not reduce social interaction after chronic social defeat stress}

To determine whether enhancing Slc6a15 levels during CSDS would restore social interaction after CSDS, we generated a Creinducible AAV to selectively express Slc6a15 in D2-neurons (Fig. $4 A, B)$. We showed that virus-mediated expression of Slc6a15 (AAV-DIO-Slc6a15-tGFP) in NAc of D2-Cre mice leads to significantly increased expression of Slc6a15 when compared with those receiving the control vector (AAV-DIO-EYFP) using a Student's $t$ test $\left(t_{(7)}=106.81, p<0.05, n=4-5\right.$ per group; Fig. $\left.4 C\right)$. Additionally, we determined the efficiency of this virus with IHC, where we show that Slc6a15-tGFP is expressed in the D2-neuron membranes in NAc of D2-Cre mice and colocalizes with antiSlc6a15 (Fig. 4D). Slc6a15 overexpression in NAc D2-neurons of mice undergoing CSDS did not produce a significant reduction in the time spent interacting with a novel social target (Fig. $4 E$ ). In contrast, D2-Cre mice receiving EYFP control virus to NAc D2neurons displayed reduced social interaction. Using a two-way ANOVA, we observed a significant main effect of stress $\left(F_{(1,31)}=\right.$ $13.05, p<0.05)$ and a significant main effect of virus $\left(F_{(1,32)}=\right.$ $0.02, p<0.05)$. A significant interaction (stress $\times$ virus) effect $\left(F_{(1,31)}=5.32, p<0.05\right)$ occurred that justified a pairwise comparison. Using a Tukey's post hoc test, we observed significance of $p<0.05$, when comparing EYFP control mice to EYFP defeat mice $(n=6-11)$. We did not observe a significant difference when comparing Slc6a15-tGFP defeat mice to all other groups (Fig. $4 E$ ). During the time spent in the interaction zone when the novel social target was absent, we did not observe a main effect of stress $\left(F_{(1,31)}=2.02, p>0.05\right)$ or a main effect of virus $\left(F_{(1,31)}=\right.$ $1.66, p>0.05)$ using a two-way ANOVA (Fig. $4 F$ ). In addition, no differences were detected in locomotion during SI between AAV-DIO-EYFP- and AAV-DIO-Slc6a15-tGFP-injected mice or the CSDS condition (control EYFP, $10071.17 \pm 635.05 \mathrm{~mm}$; control Slc6a15-tGFP, $9163.63 \pm 774.82 \mathrm{~mm}$; defeat EYFP, 8521.23 \pm 869.50; defeat Slc6a15-tGFP, 8057.10 \pm 774.20). Twoway ANOVA showed no main effects of stress $\left(F_{(1,31)}=2.7, p>\right.$ $0.05)$ or virus $\left(F_{(1,31)}=0.71, p>0.05\right)$.

\section{Reduced Slc6a15 in D2-MSNs but not ChAT interneurons induces stress susceptibility}

Slc6a15 in situ hybridization [Allen Brain Atlas (www.brain-map. org)] shows Slc6a15 expression in medium- and large-sized neurons in NAc, suggesting that it colocalizes to the large ChAT interneurons along with D2-MSNs. Additionally, D2 is expressed in the ChAT interneurons (Alcantara et al., 2003). Thus, we next examined Slc6a15 protein in ChAT interneurons in NAc of D2- 
GFP mice that underwent CSDS. Using an anti-ChAT antibody, we observed Slc6a15 protein in a high percentage of ChAT interneurons of nonstressed controls (Fig. 5A,B). Further, Slc6a15 protein colocalization with ChAT interneurons was unaltered in CSDS-susceptible and resilient mice compared with nonstressed control mice by one-way ANOVA $\left(F_{(2,8)}=2.85, p>0.05, n=\right.$ 3-4/group; Fig. 5B). These data suggest that reduced Slc6a15 occurs selectively in D2-MSNs of susceptible mice. Additionally, this implies that the ability to alter behavioral responses to stress by genetic perturbation of Slc6a15 is likely occurring through D2-MSNs (Figs. 3, 4). To directly test this, we injected AAV-DIOSlc6a15miR-mCitrine or AAV-DIO-SSmiR-mCitrine control virus into the NAc of A2A-Cre mice (Fig. $5 C, D$ ), which express Cre in D2-MSNs but not ChAT interneurons (Gerfen et al., 2013). Genetic reduction of Slc6a15 in NAc D2-MSNs of A2A-Cre mice significantly reduced time in the interaction zone with a novel social target present. Analysis with a two-way ANOVA demonstrated a main effect of virus $\left(F_{(1,27)}=10.53, p<0.01\right)$ and main effect of stress $\left(F_{(1,27)}=7.08, p<0.05\right)$. A significant interaction was not observed, however, we performed a planned pairwise comparison using a Tukey's post hoc test based on the observations in the D2-Cre knock-down experiments in Figure $3 H$. The post hoc test resulted in a significance of $p<0.05$ when comparing the Slc6a15-miR defeat group to all other groups (Fig. $5 E$ ). The interaction time with the novel target appeared to be reduced in Slc6a15-miR mice compared with SSmiR mice in the nonstressed group; however, the post hoc comparison was not significant. Time spent in the interaction zone without the novel social target was unaltered among all groups. A two-way ANOVA revealed a main effect of stress $\left(F_{(1,27)}=6.70, p<0.05\right)$ but a lack of a main effect of virus $\left(F_{(1,27)}=1.62, p>0.05\right)$ or an interaction effect (stress $\times$ virus; $F_{(1,27)}=2.31, p>0.05$; Fig. $5 F$ ). This main effect of stress was not a consequence of locomotor activity since no difference in locomotion was observed during SI in AAV-DIOSSmiR- and AAV-DIO-Slc6a15miR-injected mice or those in the CSDS condition (control SSmiR, $7111.65 \pm 634.57 \mathrm{~mm}$; control Slc6a15miR, $7601.80 \pm 488.88 \mathrm{~mm}$; defeat SSmiR, $7604.456 \pm$ 956.68; defeat Slc6a15miR, $6097.80 \pm 880.65)$. Using a two-way ANOVA, we did not observe main effects of stress $\left(F_{(1,27)}=0.42\right.$, $p>0.05)$ or virus $\left(F_{(1,27)}=0.42, p>0.05\right)$.

\section{Discussion}

The present study examined the role for Slc6a15 in NAc D2neurons in stress susceptibility. We first demonstrated that Slc6a15, which was previously shown to be a genetic risk factor for MDD (Kohli et al., 2011; Schuhmacher et al., 2013), is reduced in NAc of mice susceptible to CSDS and in NAc of individuals with MDD who were receiving medication and were not receiving medication who committed suicide. These findings are consistent with a previous study (Kohli et al., 2011) demonstrating reduced Slc6a15 in the hippocampus of individuals with MDD and in rodents after chronic stress. We further went on to examine Slc6a15 in NAc D2-neurons in stress susceptibility. We first verified that Slca615 was enriched in NAc D2-neurons compared with D1-neurons, using the RiboTag methodology to isolate ribosome-associated mRNA from NAc D2- and D1-neurons. The enrichment of Slc6a15 in NAc D2-neurons was consistent with our previous study, using fluorescence-activated cell sorting of D2- vs D1-neurons to demonstrate enriched Slc6a15 mRNA in D2-neurons in striatum (both dorsal striatum and nucleus accumbens; Lobo et al., 2006). Interestingly, we observed Slc6a15 colocalization with only $38.84 \%$ of D2-neurons. This could reflect a subpopulation of D2-neurons or a threshold limit of
Slc6a15 detection. Despite a large number of studies examining the D2-neuron and D1-neuron populations in dorsal and ventral striatum, the information on subpopulations within these neuron subtypes is poor. Future examination of this potential D2/ Slc6a15-neuron subpopulation would be informative for the understanding of D2-neuron subtype function in the normal brain as well as for a further understanding of D2-neuron function in stress susceptibility.

To determine whether the reduction of Slc6a15 in D2-neurons is associated with susceptibility to stress, we engineered a Slc6a15-miR to selectively knock down Slc6a15 levels in NAc D2-neurons. The reduction of Slc6a15 in D2-neurons using D2-Cre mice caused a reduction of the social interaction time with a novel social target after SSDS, implicating that reduced Slc6a15 levels in D2neurons enhances vulnerability to SSDS. We further show that this reduction of Slc6a15 in D2-neurons is specific to NAc D2MSNs and not ChAT interneurons, which also express D2 and Slc6a15. Using A2A-Cre mice, which express Cre in D2-MSNs but not ChAT interneurons, we also observed a stress-susceptible outcome with miR-mediated Slc6a15 reduction. Our data are in line with our previous study demonstrating a role for NAc D2neurons in inducing a susceptible outcome to SSDS (Francis et al., 2015).

While we demonstrated a role for reduced Slc6a15 in NAc D2-neurons in mediating susceptibility to stress, it is unclear how reduced Slc6a15 levels in D2-neurons are causing the susceptible outcomes. Slc6a15 is a neutral amino acid transporter that has high affinity for proline, leucine, and methionine transport (Bröer et al., 2006). Previous work examining Slc6a15 in hippocampus demonstrates that a lack of Slc6a15 causes reduced Slc6a15 amino acid transport (Drgonova et al., 2007; Santarelli et al., 2015). The reduction of proline, a precursor of glutamate, potentially dysregulates glutamate levels in hippocampus (Kohli et al., 2011; Santarelli et al., 2015, 2016). D2-MSNs are GABAergic projection neurons and do not release glutamate. However, as glutamate is a metabolic precursor for GABA (Bak et al., 2006), it is plausible that a reduction of glutamate amino acid precursors, through a reduction of Slc6a15, can ultimately alter GABA metabolism. D2MSNs are also highly enriched in the enkephalin neuropeptides (Gerfen and Young, 1988; Lobo et al., 2006), with the two major enkephalins being methionine-enkephalin and leucine-enkephalin (Penny et al., 1986). Thus, it is also possible that reduced Slca615 can ultimately affect enkephalin levels by reducing methionine and leucine transport. Another potential mechanism through which reduced Slc6a15 in D2-MSNs might have downstream molecular repercussions and might lead to stress susceptibility, is DNA methylation. If Slc6a15 reduction disrupts methionine transport in D2-MSNs, DNA methylation patterns in these neurons could be altered, since methionine is a methyl donor that can impact DNA methylation (Niculescu and Zeisel, 2002). Previous studies have demonstrated altered DNA methyltransferase in NAc in stress susceptibility (LaPlant et al., 2010; Hodes et al., 2015). Further, methionine supplementation has been demonstrated to have antidepressant potential (Rosenbaum et al., 1990). Future studies examining the precise mechanisms by which reduced Slc6a15 in D2-MSNs alters neurotransmitter content or methioninerelated processes are needed to fully understand the role of Slc6a15 in stress susceptibility.

Consistent with the enhanced social avoidance following SSDS with reduced Slc6a15 in NAc D2-neurons, restoring Slc6a15 expression to D2-neurons prevented reductions in social interaction following CSDS. Future studies should investigate upstream positive regulators of Slc6a15 expression that exist in D2-neurons or other 
vulnerable brain regions or neuron populations with altered Slc6a15 levels. However, although Slc6a15 overexpression in D2neurons prevented an overall reduction in social interaction following CSDS, not all of the mice with Slc6a15 overexpression displayed a resilient outcome. It is plausible that the overexpression of Slc6a15 levels in D2-neurons does not entirely restore Slc6a15 function. Future studies examining the mechanistic action of Slc6a15 in D2-neurons and whether its function is compromised in stress susceptibility will provide improved information for targeting Slc6a15 in D2-neurons for resilient outcomes to stress.

Collectively, our studies show that the previously identified depression risk gene, Slc6a15, is reduced at both the mRNA and protein level in NAc D2-MSNs. Consistent with this, Slc6a15 mRNA is reduced in NAc of individuals with MDD, and genetic reduction of Slc6a15 in D2-neurons mediates CSDS susceptibility. Overall, our studies implicate a role for reduced Slc6a15 levels in the NAc D2-neuron population as an underlying factor of stress susceptibility.

\section{References}

Alcantara AA, Chen V, Herring BE, Mendenhall JM, Berlanga ML (2003) Localization of dopamine D2 receptors on cholinergic interneurons of the dorsal striatum and nucleus accumbens of the rat. Brain Res 986:22-29. CrossRef Medline

Bak LK, Schousboe A, Waagepetersen HS (2006) The glutamate/GABAglutamine cycle: aspects of transport, neurotransmitter homeostasis and ammonia transfer. J Neurochem 98:641-653. CrossRef Medline

Berton O, McClung CA, Dileone RJ, Krishnan V, Renthal W, Russo SJ, Graham D, Tsankova NM, Bolanos CA, Rios M, Monteggia LM, Self DW, Nestler EJ (2006) Essential role of BDNF in the mesolimbic dopamine pathway in social defeat stress. Science 311:864-868. CrossRef Medline

Bröer A, Tietze N, Kowalczuk S, Chubb S, Munzinger M, Bak LK, Bröer S (2006) The orphan transporter v7-3 (slc6a15) is a Na+-dependent neutral amino acid transporter (B0AT2). Biochem J 393:421-430. CrossRef Medline

Broer S (2013) Diseases associated with general amino acid transporters of the solute carrier 6 family (SLC6). Curr Mol Pharmacol 6:74-87. CrossRef Medline

Chandra R, Francis TC, Konkalmatt P, Amgalan A, Gancarz AM, Dietz DM, Lobo MK (2015) Opposing role for Egr3 in nucleus accumbens cell subtypes in cocaine action. J Neurosci 35:7927-7937. CrossRef Medline

Dias C, Feng J, Sun H, Shao NY, Mazei-Robison MS, Damez-Werno D, Scobie K, Bagot R, LaBonté B, Ribeiro E, Liu X, Kennedy P, Vialou V, Ferguson D, Peña C, Calipari ES, Koo JW, Mouzon E, Ghose S, Tamminga C, et al (2014) beta-catenin mediates stress resilience through Dicer1/microRNA regulation. Nature 516:51-55. CrossRef Medline

Drgonova J, Liu QR, Hall FS, Krieger RM, Uhl GR (2007) Deletion of v7-3 (SLC6A15) transporter allows assessment of its roles in synaptosomal proline uptake, leucine uptake and behaviors. Brain Res 1183:10-20. CrossRef Medline

Eichler AJ, Antelman SM (1979) Sensitization to amphetamine and stress involve in nucleus accumbens and medial frontal cortex. Brain Res 176: 412-416. CrossRef Medline

Francis TC, Chandra R, Friend DM, Finkel E, Dayrit G, Miranda J, Brooks JM, Iñiguez SD, O’Donnell P, Kravitz A, Lobo MK (2015) Nucleus accumbens medium spiny neuron subtypes mediate depression-related outcomes to social defeat stress. Biol Psychiatry 77:212-222. CrossRef Medline

Gerfen CR, Young WS 3rd (1988) Distribution of striatonigral and striatopallidal peptidergic neurons in both patch and matrix compartments: an in situ hybridization histochemistry and fluorescent retrograde tracing study. Brain Res 460:161-167. CrossRef Medline

Gerfen CR, Paletzki R, Heintz N (2013) GENSAT BAC cre-recombinase driver lines to study the functional organization of cerebral cortical and basal ganglia circuits. Neuron 80:1368-1383. CrossRef Medline

Golden SA, Christoffel DJ, Heshmati M, Hodes GE, Magida J, Davis K, Cahill ME, Dias C, Ribeiro E, Ables JL, Kennedy PJ, Robison AJ, GonzalezMaeso J, Neve RL, Turecki G, Ghose S, Tamminga CA, Russo SJ (2013)
Epigenetic regulation of RAC1 induces synaptic remodeling in stress disorders and depression. Nat Med 19:337-344. CrossRef Medline

Gong S, Zheng C, Doughty ML, Losos K, Didkovsky N, Schambra UB, Nowak NJ, Joyner A, Leblanc G, Hatten ME, Heintz N (2003) A gene expression atlas of the central nervous system based on bacterial artificial chromosomes. Nature 425:917-925. CrossRef Medline

Gong S, Doughty M, Harbaugh CR, Cummins A, Hatten ME, Heintz N, Gerfen CR (2007) Targeting Cre recombinase to specific neuron populations with bacterial artificial chromosome constructs. J Neurosci 27: 9817-9823. CrossRef Medline

Hägglund MG, Roshanbin S, Löfqvist E, Hellsten SV, Nilsson VC, Todkar A, Zhu Y, Stephansson O, Drgonova J, Uhl GR, Schiöth HB, Fredriksson R (2013) B(0)AT2 (SLC6A15) is localized to neurons and astrocytes, and is involved in mediating the effect of leucine in the brain. PLoS One 8:e58651. CrossRef Medline

Hahn MK, Blakely RD (2007) The functional impact of SLC6 transporter genetic variation. Annu Rev Pharmacol Toxicol 47:401-441. CrossRef Medline

Han C, Yeh TL, Kato M, Sato S, Chang CM, Pae CU (2013) Management of chronic depressive patients with residual symptoms. CNS Drugs 27 [Suppl 1]:S53-S57. CrossRef

Hodes GE, Pfau ML, Purushothaman I, Ahn HF, Golden SA, Christoffel DJ, Magida J, Brancato A, Takahashi A, Flanigan ME, Ménard C, Aleyasin H, Koo JW, Lorsch ZS, Feng J, Heshmati M, Wang M, Turecki G, Neve R, Zhang B, et al (2015) Sex differences in nucleus accumbens transcriptome profiles associated with susceptibility versus resilience to subchronic variable stress. J Neurosci 35:16362-16376. CrossRef Medline

Kohli MA, Lucae S, Saemann PG, Schmidt MV, Demirkan A, Hek K, Czamara D, Alexander M, Salyakina D, Ripke S, Hoehn D, Specht M, Menke A, Hennings J, Heck A, Wolf C, Ising M, Schreiber S, Czisch M, Müller MB, et al (2011) The neuronal transporter gene SLC6A15 confers risk to major depression. Neuron 70:252-265. CrossRef Medline

Krishnan V, Han MH, Graham DL, Berton O, Renthal W, Russo SJ, Laplant Q, Graham A, Lutter M, Lagace DC, Ghose S, Reister R, Tannous P, Green TA, Neve RL, Chakravarty S, Kumar A, Eisch AJ, Self DW, Lee FS, et al (2007) Molecular adaptations underlying susceptibility and resistance to social defeat in brain reward regions. Cell 131:391-404. CrossRef Medline

LaPlant Q, Vialou V, Covington HE 3rd, Dumitriu D, Feng J, Warren BL, Maze I, Dietz DM, Watts EL, Iñiguez SD, Koo JW, Mouzon E, Renthal W, Hollis F, Wang H, Noonan MA, Ren Y, Eisch AJ, Bolaños CA, Kabbaj M, et al (2010) Dnmt3a regulates emotional behavior and spine plasticity in the nucleus accumbens. Nat Neurosci 13:1137-1143. CrossRef Medline

Li M, Ge T, Feng J, Su B (2013) SLC6A15 rs1545843 and depression: implications from brain imaging data. Am J Psychiatry 170:805. CrossRef Medline

Lobo MK, Zaman S, Damez-Werno DM, Koo JW, Bagot RC, DiNieri JA, Nugent A, Finkel E, Chaudhury D, Chandra R, Riberio E, Rabkin J, Mouzon E, Cachope R, Cheer JF, Han MH, Dietz DM, Self DW, Hurd YL, Vialou V, et al (2013) DeltaFosB induction in striatal medium spiny neuron subtypes in response to chronic pharmacological, emotional, and optogenetic stimuli. J Neurosci 33:18381-18395. CrossRef Medline

Lobo MK, Karsten SL, Gray M, Geschwind DH, Yang XW (2006) FACSarray profiling of striatal projection neuron subtypes in juvenile and adult mouse brains. Nat Neurosci 9:443-452. CrossRef Medline

Niculescu MD, Zeisel SH (2002) Diet, methyl donors and DNA methylation: interactions between dietary folate, methionine and choline. J Nutr 132:2333S-2335S. Medline

Penny GR, Afsharpour S, Kitai ST (1986) The glutamate decarboxylase-, leucine enkephalin-, methionine enkephalin- and substance P-immunoreactive neurons in the neostriatum of the rat and cat: evidence for partial population overlap. Neuroscience 17:1011-1045. CrossRef Medline

Robison AJ, Vialou V, Sun HS, Labonte B, Golden SA, Dias C, Turecki G, Tamminga C, Russo S, Mazei-Robison M, Nestler EJ (2014) Fluoxetine epigenetically alters the CaMKIIalpha promoter in nucleus accumbens to regulate DeltaFosB binding and antidepressant effects. Neuropsychopharmacology 39:1178-1186. CrossRef Medline

Rosenbaum JF, Fava M, Falk WE, Pollack MH, Cohen LS, Cohen BM, Zubenko GS (1990) The antidepressant potential of oral S-adenosyl-1methionine. Acta Psychiatr Scand 81:432-436. CrossRef Medline

Rudnick G, Krämer R, Blakely RD, Murphy DL, Verrey F (2014) The SLC6 transporters: perspectives on structure, functions, regulation, 
and models for transporter dysfunction. Pflugers Arch 466:25-42. CrossRef Medline

Russo SJ, Nestler EJ (2013) The brain reward circuitry in mood disorders. Nat Rev Neurosci 14:609-625. CrossRef Medline

Santarelli S, Namendorf C, Anderzhanova E, Gerlach T, Bedenk B, Kaltwasser S, Wagner K, Labermaier C, Reichel J, Drgonova J, Czisch M, Uhr M, Schmidt MV (2015) The amino acid transporter SLC6A15 is a regulator of hippocampal neurochemistry and behavior. J Psychiatr Res 68:261269. CrossRef Medline

Santarelli S, Wagner KV, Labermaier C, Uribe A, Dournes C, Balsevich G, Hartmann J, Masana M, Holsboer F, Chen A, Müller MB, Schmidt MV (2016) SLC6A15, a novel stress vulnerability candidate, modulates anxiety and depressive-like behavior: involvement of the glutamatergic system. Stress 19:83-90. CrossRef Medline

Sanz E, Yang L, Su T, Morris DR, McKnight GS, Amieux PS (2009) Celltype-specific isolation of ribosome-associated mRNA from complex tissues. Proc Natl Acad Sci U S A 106:13939-13944. CrossRef Medline

Schuhmacher A, Lennertz L, Wagner M, Höfels S, Pfeiffer U, Guttenthaler V, Maier W, Zobel A, Mössner R (2013) A variant of the neuronal amino acid transporter SLC6A15 is associated with ACTH and cortisol responses and cognitive performance in unipolar depression. Int J Neuropsychopharmacol 16:83-90. CrossRef Medline

Vialou V, Cui H, Perello M, Mahgoub M, Yu HG, Rush AJ, Pranav H, Jung S, Yangisawa M, Zigman JM, Elmquist JK, Nestler EJ, Lutter M (2011) A role for DeltaFosB in calorie restriction-induced metabolic changes. Biol Psychiatry 70:204-207. CrossRef Medline

Virk MS, Sagi Y, Medrihan L, Leung J, Kaplitt MG, Greengard P (2016) Opposing roles for serotonin in cholinergic neurons of the ventral and dorsal striatum. Proc Natl Acad Sci U S A 113:734-739. CrossRef Medline

Warner-Schmidt JL, Schmidt EF, Marshall JJ, Rubin AJ, Arango-Lievano M, Kaplitt MG, Ibañez-Tallon I, Heintz N, Greengard P (2012) Cholinergic interneurons in the nucleus accumbens regulate depression-like behavior. Proc Natl Acad Sci U S A 109:11360-11365. CrossRef Medline

Willner P, Muscat R, Papp M (1992) Chronic mild stress-induced anhedonia: a realistic animal model of depression. Neurosci Biobehav Rev 16: 525-534. CrossRef

Zacharko RM1, Lalonde GT, Kasian M, Anisman H (1987) Strain-specific effects of inescapable shock on intracranial self-stimulation from the nucleus accumbens. Brain Res 1:164-168. Medline 